\title{
Educational campaign versus malathion spraying for the control of Aedes aegypti in Colima, Mexico
}

\author{
F Espinoza-Gómez, C Moises Hernández-Suárez, R Coll-Cárdenas
}

J Epidemiol Community Health 2002;56:148-152

\begin{abstract}
Objective: To evaluate the effect of an educational campaign for reducing the breeding places of Aedes aegypti, the principal vector of dengue; and to compare its effects with the ones obtained by spraying of malathion at ultralow volume.

Design: Randomised community trial.

Setting: Colima city, in the State of Colima, Mexico.

Participants: Householders of 187 houses, randomly selected from the west sector of the city.

Data: In each house, an entomological survey was done, as well as one for knowledge, attitude and practices (KAP), before the intervention and six months after. The intervention consisted of educational campaign alone (47 houses); malathion spraying at ultra low volume alone (46 houses); both treatments simultaneously (49 houses) and no intervention, or control group (45 houses). Main results: The global average of the positive containers by house $(C+/ C)$ was reduced from 0.97 to 0.77 . A two way analysis of variance showed that this reduction was more apparent in the houses that received educational campaign $(F=8.4, p<0.005)$ with relation to the ones that received malathion spraying $(F=0.38, p>0.5)$, while the combination of both treatments demonstrated a discrete negative interaction $(F=6.52, p<0.05)$. These effects were independent of climatic changes and level of knowledge about dengue, as the KAP indicator did not show any significant changes in any group $(F=1.14$, p>0.1).

Conclusion: The results indicated that the educational campaign reduced the $A$ aegypti breeding places more effectively than the use of chemicals spraying, and that the combination of both treatments can reduce its efficiency, possibly because of the false expectancy of protection that spraying creates. The KAP surveys seemed to have very limited value in evaluating quantitatively the programmes of eradication of the dengue vector.
\end{abstract}

See end of article for authors' affiliations

Correspondence to: Dr F Espinoza-Gómez, Facultad de Medicina, Universidad de Colima Avenida Universidad 333, Colonia las Víboras, CP 28040, Colima, Colima, México;

fespin@cgic.ucol.mx

Accepted for publication 8 June 2001

D engue and dengue haemorrhagic fever represent one of the greatest challenge to public health at a world level. Each year approximately 20000000 persons become ill and 35000 die from this illness. ${ }^{1}$ Adding to the loss of human lives, each outbreak causes severe damage to the economy and to the welfare of the affected communities, as the economical costs can reach $\$ 10$ per person. ${ }^{2}$ From a social point of view, dengue can cause estimated losses up to 57000 discapacity adjusted life years per million of people in some studied communities, which is higher than that observed with other transmissible sicknesses, such as, tuberculosis and viral hepatitis. ${ }^{3}$ For these reasons, a relatively benign illness like dengue, has received growing attention as a priority for public health. ${ }^{45}$

The uncontrollable re-emergence of dengue is directly related with the presence of its vector, the Aedes mosquito (Diptera, Culicidae), especially the cosmopolitan Aedes aegypti (L). The expansion of the mosquito populations can be explained by many factors, including demographic explosion, global warming and growing traffic of people between the infested communities and those previously vector free. ${ }^{6}$ In the same manner, the persistent application of vertical strategies based on the use of spatial sprayings of insecticide, adding to the lack of trustworthy programmes of surveillance, have also contributed to this alarming re-emergence..$^{78}$ It is because of this that most experts agree that the best strategy for dengue control would be to uphold a proactive participation of the community, so that each habitant takes responsibility and the initiative to attempt to eliminate the breeding places of the mosquito by means of hygienic improvement and house maintenance, as almost always the mosquito is inside such areas. $^{9}{ }^{10}$ Despite this consensus regarding the importance that community participation has for the control of Aedes aegypti and with that, for dengue prevention; it is not clear when, where and how such programmes should be applied. In addition, no quantitative evaluation has been done on the effects that such strategies could have, even when some authors report discrete reductions of the named "larval indices" by application of educational programmes, ${ }^{11}$ other investigators have found no significant changes in such indicators. ${ }^{9}$ The larval indices (house, containers and Breteau index), continue being the principal parameter for estimating the Aedes aegypti populations, despite its evident limitations. ${ }^{12}$

On the other hand, surveys related with knowledge, attitude and practices (KAP) about dengue have been used to evaluate the educational campaigns, but their results are weak and inconclusive. ${ }^{111314}$ Also, no study was found that compared in a quantitative way the effect on the larval indices of an educational campaign, or that made any comparison with the results from the application of insecticide spraying. This type of information would be vital in the decision making for the control programme's planning and application.

In this study, a prospective evaluation was done of an educational campaign for the elimination of Aedes aegypti breeding places based on the community participation, through the density changes of the containers with mosquito larvae. These effects are compared with the ones obtained by using traditional insecticide spraying at ultralow volume (ULV) and with the absence of any type of management. The study was

Abbreviations: KAP, knowledge, attitude and practices; ULV, ultralow volume; EC, educational campaign 
done in the city of Colima, located in the Mexican Pacific Basin, which is infested with Aedes aegypti and has shown epidemic outbursts of dengue during the years of 1996 and 1997. ${ }^{15}$

\section{METHODS}

\section{Localisation and study design}

The city of Colima, capital of the State of Colima, Mexico, is located in the Mexican Pacific coast at $19^{\circ} 15^{\prime} \mathrm{N}$ and $103^{\circ} 43^{\prime}$ W. It has a population of 120780 habitants, a semi-humid and warm climate, an annual average temperature of $25.2^{\circ} \mathrm{C}$, and annual average pluvial precipitation of $1010 \mathrm{ml}$. Its altitude is $490 \mathrm{~m}$ above sea level. ${ }^{16}$ The study was done in the west end of the city where a project named "A New Initiative" (Programa UNI-Colima) has been developing for more than eight years and is sponsored by the University of Colima and the WK Kellogg Foundation. This project consists of a series of activities directed to encourage the active participation of the community in the resolution of their health problems. These activities, in which the natural leaders of the community get involved, as well as the university, some municipal and state health authorities, are in accordance with the recommended outlines by the Local Health Systems. ${ }^{17}{ }^{18}$ The UNI programme covers an approximate surface of $20 \mathrm{~km}^{2}$, with an estimated population of 30000 persons.

This was a randomised community trial, in which the observational units were 187 houses, randomly selected by means of a draw from between approximately 7000 houses in the west end of Colima. This area was chosen because of the homogeneous socioeconomic conditions of the habitants and the access to public services, in such a way, they are non-stratified variables. The 187 houses were grouped in four blocks, in accordance to type of received intervention: the first block (A), consisted of 46 houses that received only malathion ULV spraying, applied by the State Secretary of Health. Block (B) was structured by 45 houses that did not receive any type of treatment (control group). Block (C) included 49 houses in which ULV were applied combined with an educational campaign and Block (D) with 47 houses where only an educational campaign was used.

\section{Sampling methods}

The sampling methods consisted of an entomological survey for surveillance of the Aedes aegypti, as recommended by the Pan American Health Organisation ${ }^{4}$; in which an operator spent about 15 minutes for each house. Inspection was done in rooms, bathrooms and patios, looking for any type of receptacle with water, with the help of a hand lantern. Only wet containers were registered and the presence of at least one larva, in any instance, was considered positive in a nominal form. Of the positive containers, a sample of larvae was taken to determine the specie and to confirm the presence of Aedes aegypti. Simultaneously to the entomological sampling, a survey was done regarding knowledge, attitude and practices relating to dengue and the vector mosquito, in accordance with the outlines recommended by Rosembaun. ${ }^{13}$ From this survey, the indicator of knowledge, attitude and practices was obtained (KAP), which was expressed in the continuous interval scale from 1 to 12 . The environmental temperature was measured in centigrade degrees $\left({ }^{\circ} \mathrm{C}\right)$ each hour, by means of an environmental thermometer at the university's observatory, which is located close to $2 \mathrm{~km}$ from the studied area. Based on this measurement, the average weekly temperature was determined during the studied period; which started in the warm rainy season (September to November 1998) and concluded in the cold dry season (February to April 1999).

\section{Treatments}

The educational campaign (EC) consisted of a series of visits house by house, done by college students of the University of

\section{Key points}

- The best preventive strategy for dengue is the proactive participation of the community to eliminate Aedes aegypti breeding places.

- This study confirms that an educational campaign with community participation is more efficient than insecticide spraying for this purpose.

- The effectiveness of such campaigns depends on previous extensive intersectorial participation in the community.

Colima. The habitants, principally housewives, were offered a talk about the importance of dengue, ways to prevent it and biological characteristics of the Aedes aegypti. Such talks were re-enforced with group meetings in which a dengue video was shown and a sociodrama was presented in the kindergarten of the area. In addition, in each visit the message was supported with a small gift, consisting of sweets, stickers and calendars related to dengue and the Aedes mosquito. The community leaders facilitated the entrance to the houses, and that way an average of three visits per house was achieved.

The insecticide application was done by personnel of the State Health Secretary of Colima by means of spatial spraying of malathion to 95\% at ULV (drop size $3 \mu$ ). A "London Fog" equipment was mounted on a pick up type truck, moving at 16 $\mathrm{km} / \mathrm{h}$, allowing an approximate dose of $120 \mathrm{mg} / \mathrm{ha}$ of insecticide. The ULV were applied following the streets of block A and $\mathrm{C}$ in cycles of seven consecutive days during October and November of 1998, and repeated in January and February 1999. At the same time, a group of technicians of the same health department, were in charge of application of granulated temefos (Abate) in each container with water that had been found in the mentioned blocks, at a doses of $1 \mathrm{ppm}$. The $\mathrm{B}$ and D blocks, even though they did not receive any ULV nor temefos in a systematic way, were occasionally subjected to those treatments when persons reported an increased nuisance by mosquito bites. In C and D blocks, where EC was applied, the population was encouraged to also use some forms of chemical or biological control, such as intradomestic sprinklers of piretroids, use of temefos, larvivorous fishes or Bacillus thuringensis; but always under their own initiative. By the conclusion of the study, confirmation had been done that the houses that should have received adequate intervention had received such. Houses were eliminated from the study if the habitants had not received adequate intervention or the proper management had not been carried out.

\section{Statistical analysis}

As well as the traditional larval indices, House, Container or Breteau index; the number of positive containers with larva by house $(\mathrm{C}+/ \mathrm{H})$ were used as the dependent variable in an interval continual scale, with its mean and standard deviation, in such a way that this variable could be analysed with the statistical parametric method, such as Student's $t$ test and the one way, or two way analysis of variance. With the purpose of exploring the correlation of $\mathrm{C}+/ \mathrm{H}$ with the temperature and the KAP index, an uni-variant unconditional logistic regression was used, where $\mathrm{C}+/ \mathrm{H}$ is expressed as a dichotomous variable, the previous weekly temperature at sampling, in a continuous scale of proportion, meanwhile KAP was transformed in a categorical multiple variable. The changes in the KAP index before and after the intervention and between the different blocks, expressed as a continual variable interval, were also analysed with the Student's $t$ test and analysis of variance. For the statistical analysis, the program Statistica for Windows 1997 was used.

\section{RESULTS}

Two hundred and fourteen houses were originally visited, but 27 were discarded as mentioned previously, so finally 
Table 1 Average positive containers to larvae per house $(\mathrm{C}+/ \mathrm{H})$ and their $95 \%$ confidence intervals $(95 \% \mathrm{Cl})$ in basal conditions and also after treatment in the four house blocks

\begin{tabular}{|c|c|c|c|c|}
\hline Treatment & $\mathrm{C}+/ \mathrm{H}$ Basal & $95 \% \mathrm{Cl}$ & $\mathrm{C}+/ \mathrm{H}$ after treatment & $95 \% \mathrm{Cl}$ \\
\hline \multicolumn{5}{|l|}{ Block A } \\
\hline Chemicals only ( $n=46$ ) & 1.108 & (0.617 to 1.59$)$ & 1.022 & $(0.575$ to 1.33$)$ \\
\hline \multicolumn{5}{|l|}{ Block B } \\
\hline Control $(n=45)$ & 1.022 & (0.651 to 1.39$)$ & 1.155 & (0.683 to 1.626$)$ \\
\hline \multicolumn{5}{|l|}{ Block C } \\
\hline Chemicals plus Education ( $n=49$ ) & 0.53 & $(0.212$ to 0.85$)$ & 0.326 & $(0.13$ to 0.521$)$ \\
\hline \multicolumn{5}{|l|}{ Block D } \\
\hline Education only ( $n=47)$ & $1.255^{*}$ & (0.879 to 1.63$)$ & $0.382 \dagger$ & $(0.122$ to 0.641$)$ \\
\hline Total $(n=187)$ & 0.973 & $(0.803$ to 1.142$)$ & $0.70 \ddagger$ & $(0.55$ to 0.85$)$ \\
\hline
\end{tabular}

*One way analysis of variance (ANOVA) for basal $\mathrm{C}+/ \mathrm{H}$ between the four house groups: $F=3.56, p<0.05$. In this case the Tukey test post ANOVA demonstrated that the most significant difference was found between $C$ (EC plus chemicals) and D (only EC), with $p<0.01 ;$ †one way ANOVA for $C+/ H$ post treatment in the four groups demonstrated a $F=8.03, p<0.0005$, with an increased difference between $C$ (EC plus Chemicals) and $B$ (Control), demonstrated by the Tukey test post ANOVA, $p<0.0001$; $¥$ Student's $t$ test for $C+/ H$ Basal $v C+/ H$ Post treatment in all the groups: $t=2.52, d f=186$, $\mathrm{p}<0.05$ (two tails).

Table 2 Changes in $\mathrm{C}+/ \mathrm{H}$ before and after treatment $(\Delta \mathrm{C}+/ \mathrm{H})$ in the two kinds of treatments, and the two way analysis of variance (ANOVA) results for the effect of each treatment

\begin{tabular}{|c|c|c|c|c|c|c|}
\hline \multirow[b]{2}{*}{ Treatment (effect) } & \multirow[b]{2}{*}{$\Delta \mathrm{C}+/ \mathrm{H}$} & \multirow[b]{2}{*}{$(95 \% \mathrm{Cl})$} & \multicolumn{4}{|c|}{ Two way ANOVA } \\
\hline & & & $\mathrm{n}$ & df & $F$ & $\mathrm{p}$ \\
\hline $\begin{array}{l}\text { Education (Blocks C and D) } \\
\text { Chemicals (Blocks A and C) } \\
\text { Control (Block B) }\end{array}$ & $\begin{array}{l}-0.53 \\
-0.18 \\
+0.133^{*}\end{array}$ & $\begin{array}{l}(-0.8 \text { to }-0.25) \\
(-0.53 \text { to }+0.18) \\
(-0.4 \text { to }+0.67)\end{array}$ & $\begin{array}{l}96 \\
95 \\
45\end{array}$ & $\begin{array}{l}183 \\
183\end{array}$ & $\begin{array}{l}8.4 \\
0.38\end{array}$ & $\begin{array}{l}0.004 \\
0.53\end{array}$ \\
\hline Interaction & & & & 183 & 6.51 & 0.01 \\
\hline
\end{tabular}

*To evaluate the basal effect $\mathrm{C}+/ \mathrm{H}$ as covariant, an analysis of covariance of $\Delta \mathrm{C}+/ \mathrm{H}$ among the four groups was performed. It showed a significant difference between them: $F=9.88, p<0.0005$, with a Tukey test between Education and Control of $\mathrm{p}<0.0001 .95 \% \mathrm{Cl}=\mathrm{confidence}$ intervals, $\mathrm{n}=$ number of cases, $d f=$ degrees of freedom, $F=$ Fisher's parameter for ANOVA, $p=$ for $F$.

completed data were obtained for for 187 houses. Table 1 shows the observed changes in the number of positive containers by house $(\mathrm{C}+/ \mathrm{H})$ in each block and by global level, before and after the intervention. The basal House Index was $54 \%$ and after treatment $41.17 \%$; Basal Container Index was $35 \%$ and after treatment $31.2 \%$; while the basal Breteau Index was 97.3 and after treatment 70 .

The most frequently infested containers with larvae in both seasons were badly covered subterranean water cisterns, followed by drums and courtyards built in washbasins ("piletas"); while in rainy season, larvae were also were found in tyres, ceramic and miscellaneous pots with water. Other types of containers were rarely infested (flower vases, drainage, roof tanks, etc). Ninety five larvae were examined, of which 82 corresponded to Aedes aegypti, (Linneo); seven to Culex pipiens q. (Say), three to Aedes epactius (Dyar and Knab) and three to Culex sp.

In table 2 changes obtained in $\mathrm{C}+/ \mathrm{H}$ by the end of each intervention are shown with each type of the treatments, as well as the analysis of such changes by means of a two way analysis of variance. The average temperature during the first part of the study (rainy warm temperature) was $24.61^{\circ} \mathrm{C}(95 \%$ CI 24.4 to 24.7), while the second part, in the dry season, was of $23.92^{\circ} \mathrm{C}(95 \%$ CI 23.1 to 24.3$)$. The logistic regression between $\mathrm{C}+/ \mathrm{H}$ and temperature did not show any significant association $(\chi=2.1, \mathrm{p}>0.5, \mathrm{OR}=0.3 ; 95 \%$ CI 0.13 to 1.67$)$. The pluvial precipitation during the period September to December 1998 was $434 \mathrm{ml}$, while for January to April 1999 period was only $4 \mathrm{ml}$.

The KAP index did not show any significant changes after the intervention of the total of houses (basal $=5.69 ; 95 \%$ CI 5.07 to $6.41 v 5.89 ; 95 \%$ CI 5.45 to 6.23 after intervention). The one way analysis of variance for the difference of basal KAP and after treatment in the four blocks also did not show any significant differences $(F=1.14, \mathrm{p}>0.1)$, while the correlation between KAP y $\mathrm{C}+/ \mathrm{H}$ showed $\chi=1.73, \mathrm{p}>0.5 ; \mathrm{OR}=0.87,95 \%$ CI 0.23 to 2.34 .

\section{DISCUSSION}

The great quantity of positive containers for larvae by house and infested houses found in this study differs notably from that informed by the Health Authorities of Colima, who rarely report values over 0.3 by house. This discrepancy is not new. Natham ${ }^{19}$ has noted that usually there exists great differences in the larval indices from when data are obtained in a simultaneous manner from an operative personnel and compared with ones recorded in works of investigation. Furthermore, the use of flashlight, originally proposed in the entomological survey and later abandoned by the official programmes, could have increased the sampling sensibility in this study, as the detection of small larvae in certain places, such as underground tanks and other very shadowed places, frequently positive to larvae, could easily go unnoticed to the eye of the most experienced technician without the help of a flashlight.

The increased frequency of $\mathrm{C}+/ \mathrm{H}$ permitted a more tough statistical parametric analysis, because of the probability of obtaining positive containers, with the number of examined houses, were sufficient to normalise a distribution curve with no need to transform the data. Despite how reasonable this assumption could be, almost all the studies relating to the analysis of larval indices are based on non-parametric statistics, assuming that the distribution of larva containers is non-Gaussian. ${ }^{12}$ In this manner, assuming that there is a normalised distribution of the $\mathrm{C}+/ \mathrm{H}$, analysis of variance by one and two ways is used, to compare the effects of the different type of treatments and for measurements before and after 
application. The total values of $\mathrm{C}+/ \mathrm{H}$ were sensitively reduced in the second phase of the study, which could be attributed at first glance to the climatic changes. Yet analysis of variance clearly shows that the EC has a much more accentuated effect than the use of chemicals and the control houses over the number of $\mathrm{C}+/ \mathrm{H}$ and because of this, they are the principal factors that reduced the larval index. In table 1 the basal values of $\mathrm{C}+/ \mathrm{H}$ were shown to be significantly higher in the $\mathrm{D}$ block (which received only EC intervention), which could lead to assuming that in that block the values of $\Delta \mathrm{C}+/ \mathrm{H}$ after the treatment could be less, even though, the covariance analysis proved that the reduction of this parameter is even more significant after the EC (as can be appreciated in table 2).

Also in table 2 it can be appreciated that two way analysis of variance showed that the effect of the EC alone had a more significant reduction of $\Delta \mathrm{C}+\mathrm{H}$ in relation to the use of ULV and to the control group, while the same analysis showed that the interaction between the EC and the use of malathion ULV reduces sensitively the effect of the first, which can be translated to a negative interaction, suggesting that the use of ULV can reduce the beneficial effect of EC. This phenomenon could be explained with the feeling of false security that is generated by the fumigating trucks passing, which makes people reduce the activities to eliminate breeding places. The presented data back the findings by Castle ${ }^{20}$ who found that the use of aerial malathion ULV do not produce significant reductions in the populations of Aedes aegypti, and are also congruent with the predictions done with mathematical simulated models that show a very brief and discrete effect of the ULV over the adult populations of Aedes aegypti. ${ }^{21}$ In this manner, the study confirms, in a quantitative manner, that an intensive EC, personalised and based on the active participation of the community leaders, is much more effective than the traditional applications of chemicals in a vertical form for the control of Aedes aegypti and the dengue transmission.

The reductions in larval indices obtained here are much more noticeable that the ones found by other similar studies. For example, Lloyd ${ }^{11}$ in Yucatan, Mexico did not find any reduction in such indices, but only a lesser increase in the same after an EC, in comparison with a control group of houses. Similarly, Rosenbaum, ${ }^{13}$ in a study in Trinidad and Tobago, did not find any significant differences in the larvae indices after applying an intense campaign of community participation. It is possible that in the present work, the previous visit, done by the UNI programme to the community, has enhanced the EC impact by facilitating the admission to the homes and the acceptance of the participating technicians in the study. Also, it is very probable that the use of permanent printed material, such as stickers and calendars, may have caused some kind of subliminal effect that might also have been favourable to the actions of the particpants to eliminate the breeding places of the mosquito. It is suggested that before programmes based in the community for the control of Aedes aegypti are implemented, they should be preceded by community actions in which different sectors are involved such as universities, local authorities, health institutions and civil organisations as has been emphasised by some authors. ${ }^{17} 22$

In this study, the environmental temperature variations and the pluvial precipitation did not show any correlation with the changes of $\mathrm{C}+/ \mathrm{H}$, which, apparently is in disagreement with that expected, as the temperature clearly influences the reproduction rate and the population density of mosquitoes. ${ }^{623}$ One probable explanation for this discordance could be that in places like Colima, where temperature fluctuations are so discrete, the impact of this climatological variable may have not the magnitude of those of areas more temperate, where habitually the field studies have been done. Therefore, the populations of Aedes aegypti could show intrinsic changes independent of the climatic variables, as has recently been proposed. ${ }^{24}$

The results of the KAP indicator did not show any significant changes or correlation with the number of $\mathrm{C}+/ \mathrm{H}$ at

\section{Policy implications}

- Preventive measures for dengue should be based on community involvement more than in the vertical use of chemicals. These programmes should include: house to house visits, involvement of natural leaders of the community and use of marketing strategies, together with quantitative evaluation of the programme.

Francisco Espinoza Gómez

Carlos M Hernández-Suárez

Rafael Coll Cárdenas

any time during the study, nor between the groups. These findings are similar to the ones reported by Rosenbaum ${ }^{13}$ and by Dias.' It would seem that in the case of dengue, this sociological parameter is incapable of detecting attitude changes at a subconscious level that induces the activities of health self maintenance, even when there is not enough knowledge and that these surveys usually do not consider the cultural context of the community, which could play a very important part in the underlying changes in the mentality towards health problems in specific communities. ${ }^{25}$ Because of this, it has recently been suggested that these kind of surveys could have a poor association with the EC outcomes ${ }^{14}$ so, perhaps the KAP surveys should be substituted by another type of tool that permits a better evaluation of the programmes against dengue and other transmissible illnesses, or at least limit their use for qualitative appraisal of the programmes.

In summary, this study shows that the use of EC house by house, preceded by an extensive work of inter-sectorial integration with the community has a clear effect on the reduction of the breeding places for Aedes aegypti and with that, the risks for transmission for dengue. The use of chemicals in the traditional manner (ULV), can delay the effect of such an EC, and for that reason, should reserved only for intense epidemical outbreaks.

\section{ACKNOWLEDGEMENTS}

We would like to thank the enthusiastic participation of the community leaders and the support of the UNI Colima Program, who facilitated the cooperation of the habitants of the study area. Also to the group of students of the University of Colima who collaborated with the field work; in particular to Julio César Barragán Anaya and Xóchitl Montoy Guzmán. Thanks to Dr Ildefonso Fernández-Salas, of the Medical Entomology Department of the Autonomous University of Nuevo Leon, México, for his observations and counselling.

Funding: this study had the support by the W K Kellogg Foundation and the Consejo Nacional de Ciencia y Tecnología (CONACYT), by way of the SIMORELOS system, grant no 1999030201.

Conflicts of interest: none.

\section{Authors' affiliations}

F Espinoza-Gómez, R Coll-Cárdenas, Faculty of Medicine, University of Colima, Colima, Mexico

C Moises Hernández-Suárez, Faculty of Sciences, University of Colima, Colima

\section{REFERENCES}

1 Pinheiro FP, Corber SJ. Global situation of dengue and dengue haemorrhagic fever, and its emergence in the Americas. World Health Stat Q 1997:50:161-9.

2 Reiter P. Status of current Aedes aegypti control methodologies. In: Halstead SB, Gómez -Dantés H. Dengue, a worldwide problem, a common strategy. Mexico: SSA/Rockefeller Foundation, 1992:41-8

3 Meltzer MI, Rigau-Perez JG, Clark GG, et al. Using disability-adjusted life years to assess the economic impact of dengue in Puerto Rico: 1984-1994. Am J Trop Med Hyg 1998;59:265-71.

4 PAHO. Dengue and dengue hemorragic fever in Americas. Guidelines for prevention and control. Washington DC, PAHO, 1994: no 548.

5 WHO. Strengthening implementation of the global strategy for Dengue fever/Dengue hemorragic fever, prevention and control. WHO/CDs/1C/ 2,000.1. Geneva: WHO, 1999 
6 Jetten TH, Focks DA. Potential changes in the distribution of dengue transmission under climate warming. Am J Trop Med Hyg 1997;57:285-97.

7 Gubler DJ. Aedes aegypti and Aedes-borne disease control in the 1990s: Top down or bottom up?. Am J Trop Med Hyg 1984:40:571-8.

8 Nathan MB. Critical review of Aedes aegypti control programmes in the Caribbean and selected neighboring countries. Am J Mosq Contr Assoc 1993; 9: 1-7.

9 Dias JC. Community participation and control of endemic diseases in Brazil: problems and possibilities Cad Saude Publica 1998:14:19-37.

10 Gubler DJ, Clark GG. Community involvement in the control of Aedes aegypti. Acta Trop 1996;61:169-79.

11 Lloyd LS, Winch P, Ortega-Canto J, et al. Results of a community-based Aedes aegypti control program in Mérida, Yucatán, México. Am J Trop Med Hyg 1992;46:635-42.

12 Service MW. Mosquito ecology, field sampling methods. New York: Elsevier Applied Science, 1993:157-67.

13 Rosenbaum J, Nathan MB, Ragoonanansingh R, et al. Community participation in Dengue prevention and control: a survey of knowledge, attitudes and practice in Trinidad and Tobago. Am J Trop Med Hyg 1995:53:1 11-17

14 IMSS. Boletín estadístico anual de mortalidad. Mexico: Instituto Mexicano del Seguro Social, 1997:24

15 INEGI. Anuario estadístico del estado de Colima. Mexico: Instituto Nacional de Estadística, Geografía e Informática, Gob. del Estado de Colima, 1998:4-10.

16 Kissil M, Chavez M. Ideario UNI. Sao Paulo, Brazil: Fundación W K Kellogg, 1994: 8-25
17 Paganini JM. Sistemas locales de salud: Un Nuevo modelo de atención en los sistemas locales de salud In: Paganini JM, Mir RC. Los sistemas locales de salud: conceptos, métodos, experiencias. Washington DC: Organización Panamericana de la Salud, Publicación científica 519, 1990:50-8

18 Nathan MB, Knudsen AB. Aedes aegypti infestation characteristics in several Caribbean countries and implications for integrated Community-based control. J Am Mosq Control Assoc 1991;7:400-4.

19 Castle T, Amador M, Rawlins S, et al. Absence of impact of aerial malathion treatment on Aedes aegypti during a dengue outbreak in Kingston, Jamaica. Rev Panam Salud Publica 1999;5:100-5.

20 Newton EA. A model of the transmission of dengue fever with an evaluation of the impact of ultra-low volume (ULV) insecticide application on dengue epidemics. Am J Trop Med Hyg 1992;47:709-20.

21 Kay BH. Intersectorial approaches to dengue vector control. Kao Hsiung I HK Tsa Chih 1994;10: S56-61.

22 Focks D, Daniels E, Haile DG, et al. A simulation model of the epidemiology of urban dengue fever: literature analysis, model development, preliminary validation, and samples of simulation results. Am J Trop Med Hyg 1995;53:489-505.

23 Hay SI, Myers MF, Burke DS, et al. Etiology of interepidemic periods of mosquito-borne disease. Proc Natl Acad Sci USA 2000;97:9335-9.

24 Koss- Chioino JD. What anthropology can contribute to tropical medicine?: overview of method for control programmes. Trop Med Int Health 1997;2:11-24

25 Degallier N, Vilarinhos PT, de Carvalho MS, et al. People's knowledge and practice about dengue, its vectors, and control means in Brasilia (DF), Brazil: its relevance with entomological factors. J Am Mosq Control Assoc 2000;16:114-23. 